Erratum

\title{
Erratum to "Strategies for Imaging Androgen Receptor Signaling Pathway in Prostate Cancer: Implications for Hormonal Manipulation and Radiation Treatment"
}

\author{
Giovanni L. Gravina, ${ }^{1,2,3}$ Claudio Festuccia, ${ }^{1}$ Pierluigi Bonfili, ${ }^{1}$ \\ Mario Di Staso, ${ }^{1}$ Pietro Franzese, ${ }^{1}$ Valeria Ruggieri, ${ }^{1}$ Vladimir M. Popov, ${ }^{3}$ \\ Vincenzo Tombolini, ${ }^{4,5}$ Carlo Masciocchi, ${ }^{6}$ Eleonora Carosa, ${ }^{7}$ Andrea Lenzi, ${ }^{2}$ \\ Emmanuele A. Jannini, ${ }^{7}$ and Ernesto Di Cesare ${ }^{1}$ \\ ${ }^{1}$ Laboratory of Radiobiology and Division of Radiotherapy, Department of Applied, Clinical and Biotechnological Sciences, \\ University of L'Aquila, Via Vetoio, Coppito 2, L'Aquila, Italy \\ ${ }^{2}$ Section of Medical Pathophysiology, Food Science and Endocrinology, Department of Experimental Medicine, \\ Sapienza University of Rome, Italy \\ ${ }^{3}$ LIPOGEN LLC, Mount Laurel, NJ, USA \\ ${ }^{4}$ Division of Radiotherapy, University of Rome, University Hospital "Policlinico Umberto I", Italy \\ ${ }^{5}$ Division of Radiotherapy, Department of Radiological Sciences, University of Rome "La Sapienza", \\ Spencer-Lorillard Foundation, Rome, Italy \\ ${ }^{6}$ Division of Radiology, Department of Applied, Clinical and Biotechnological Sciences, University of L'Aquila, L'Aquila, Italy \\ ${ }^{7}$ Course of Endocrinology and Medical Sexology, Department of Applied, Clinical and Biotechnological Sciences, \\ University of L'Aquila, L'Aquila, Italy \\ Correspondence should be addressed to Giovanni L. Gravina; giovanniluca.gravina@libero.it
}

Received 3 February 2014; Accepted 6 February 2014; Published 9 March 2014

Copyright (C) 2014 Giovanni L. Gravina et al. This is an open access article distributed under the Creative Commons Attribution License, which permits unrestricted use, distribution, and reproduction in any medium, provided the original work is properly cited.

The name of the first author (Gravina Giovanni Luca) was incorrect and is corrected here as Giovanni L. Gravina. 


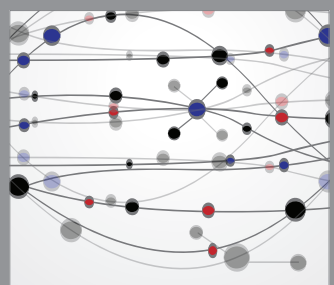

The Scientific World Journal
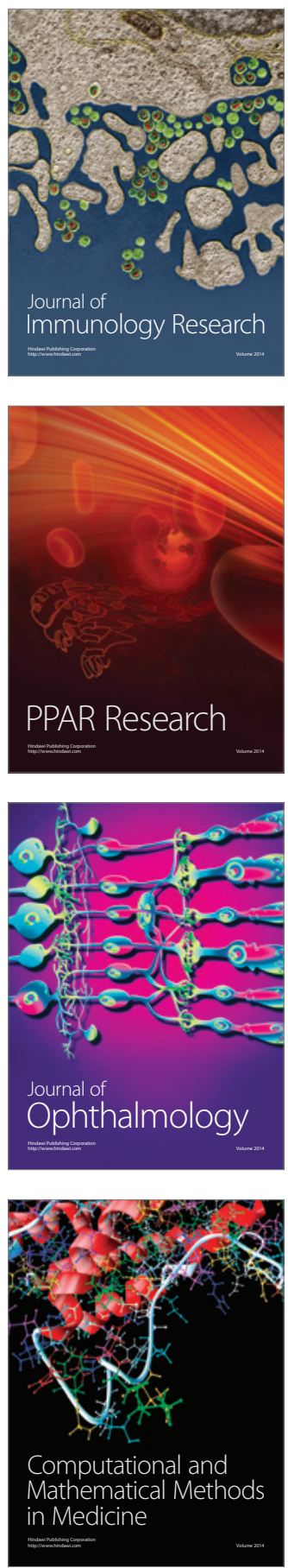

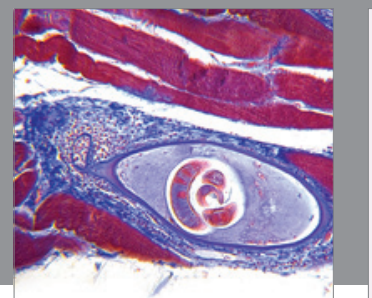

Gastroenterology

Research and Practice
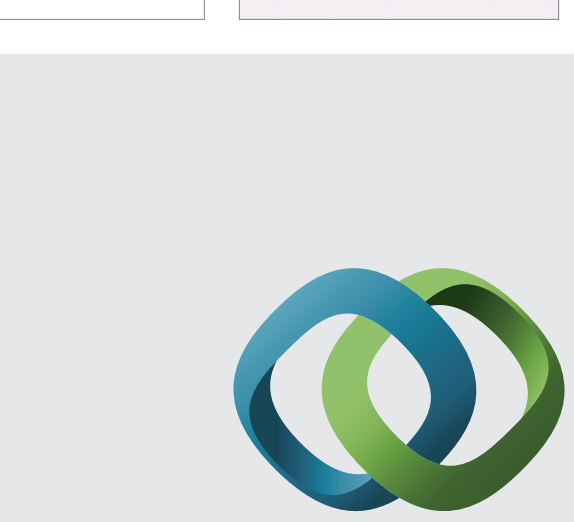

\section{Hindawi}

Submit your manuscripts at

http://www.hindawi.com
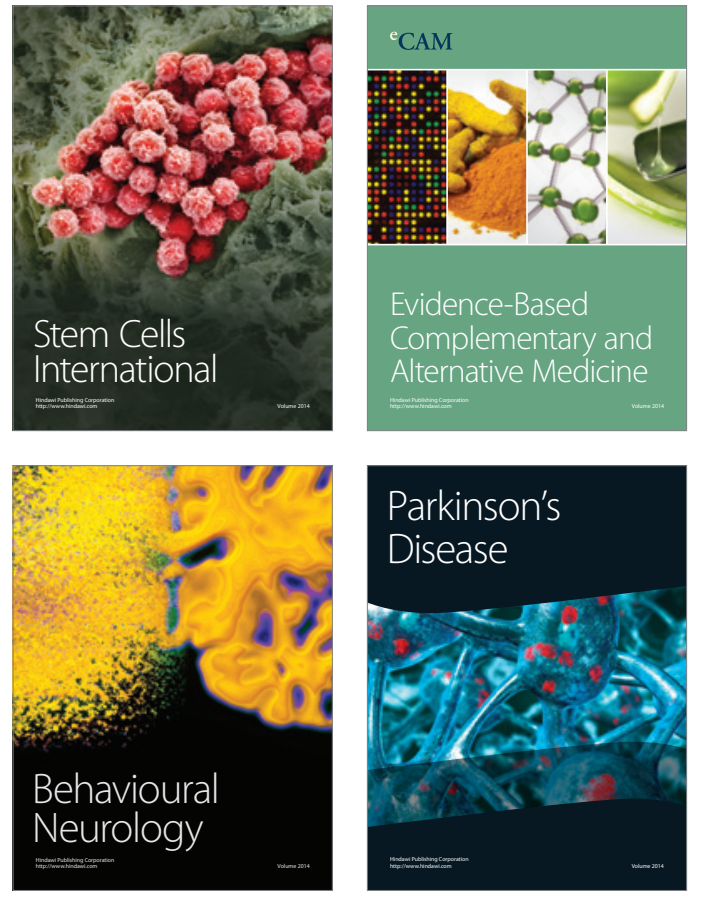
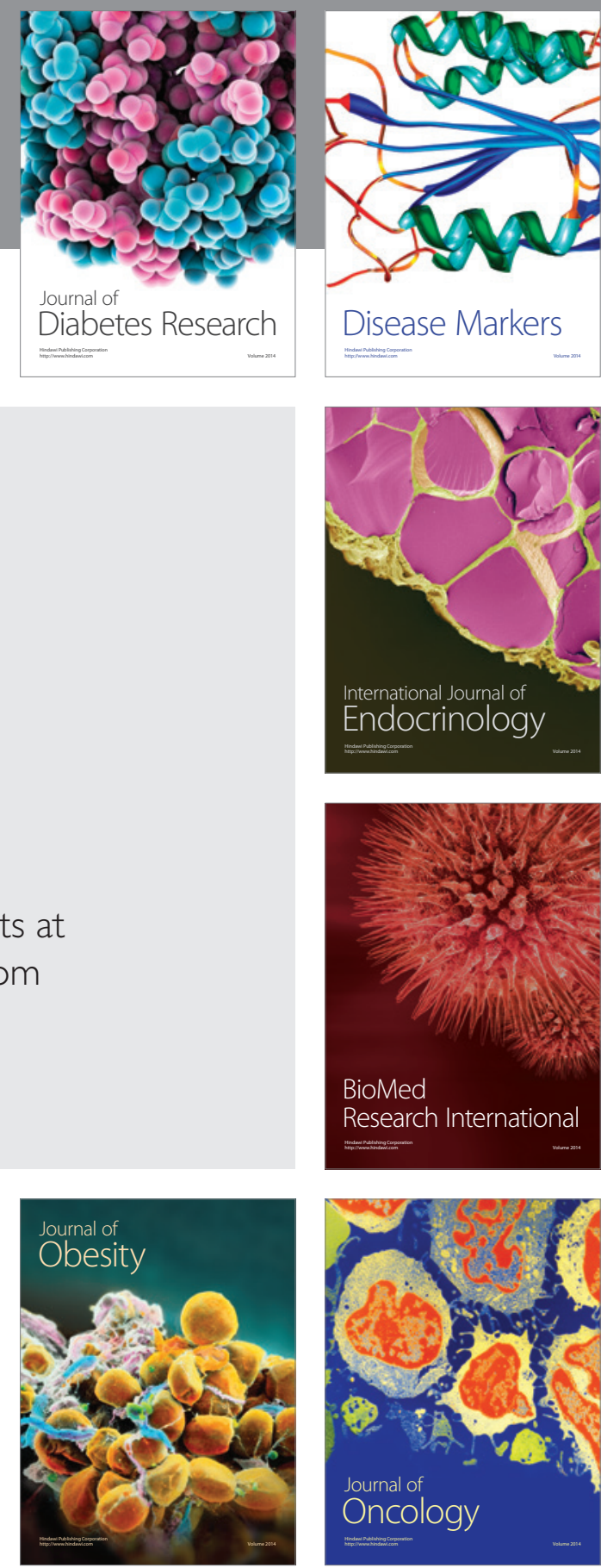

Disease Markers
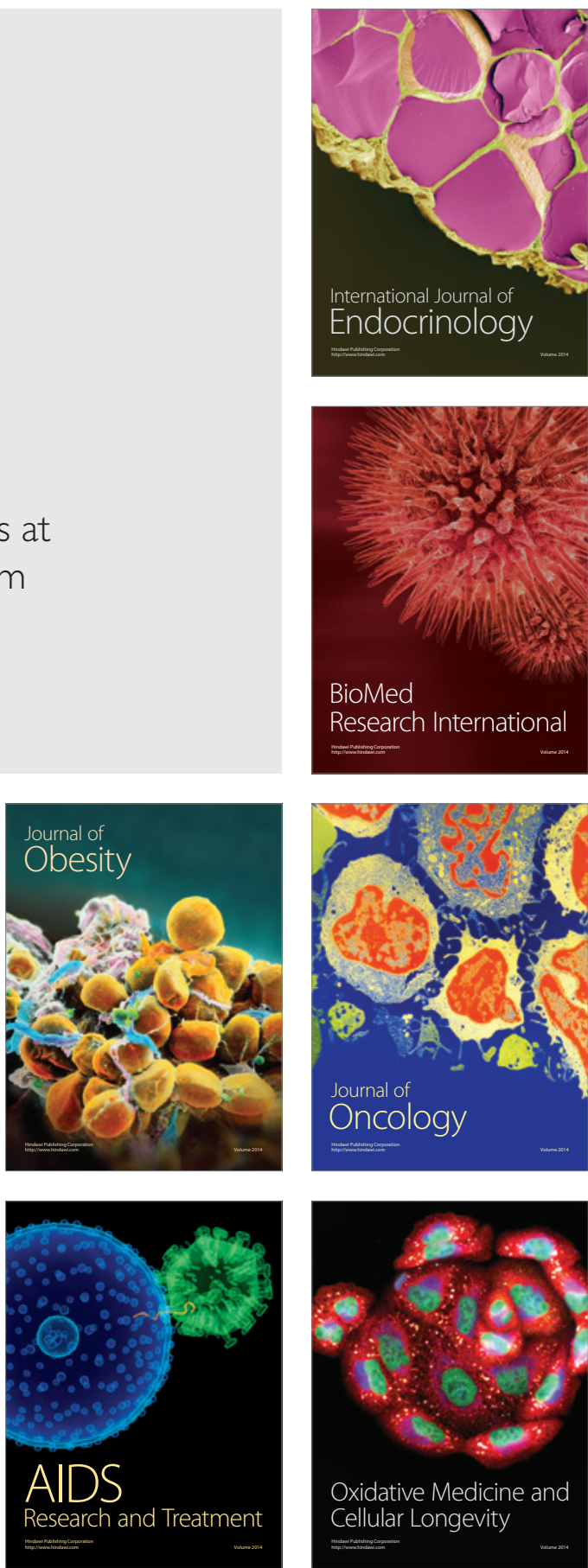